\title{
COPLAS SEFARDÍES Y PLIEGOS DE CORDEL HISPÁNICOS
}

JOSÉ MANUEL PEDROSA

Para cualquier persona iniciada en ambos géneros, la lectura de coplas sefardíes y de poesía de pliegos de cordel hispánicos -españoles, portugueses, hispanoamericanos- es fácil que le produzca la impresión, espontánea y casi subconsciente, de estar ante mundos poéticos cercanos entre sí. Desde las primeras lecturas, el carácter narrativo, el tono enunciativo, la artificiosidad formulística convertida ocasionalmente en cliché recurrente, el trasfondo ideológico - a menudo moral - subyacente en muchas composiciones, dan a ambos géneros un reconocible aire de familia. Hoy, la simple intuición nacida de lecturas dispersas puede ser ya sustituida por certezas asentadas sobre firmes bases científicas comparativas, puesto que en los últimos años se han puesto a nuestra disposición ediciones e instrumentos de análisis crítico suficientes para un acercamiento global y profundo al género de las coplas sefardíes. Las recientemente aparecidas Bibliografía analítica de ediciones de coplas sefardíes (= BAECS) ' y las Coplas sefardíes: primera selección ${ }^{2}$ de Elena Romero, prologadas ambas por Iacob M. Hassán, más los artículos previos de ambos sobre el tema - y la promesa de otros trabajos sobre la materia-, ponen al alcance del público especializado y medio una representación cuantitativa y cualitativamente importante del género, al que abren perspectivas de crítica literaria hasta hace poco insospechadas -o sospechadas por muy pocos - que acabarán previsiblemente por situarlo en la relevante posición que le corresponde en el panorama de la poesía - y de los estudios poéticos- en las lenguas hispanas.

Con estas bases textuales y catalográficas, esa intuición elemental que al principio puede surgir de la lectura no sistemática de coplas

\footnotetext{
1 Publicada en Madrid por el CSIC en 1992.

${ }^{2}$ Publicada en Córdoba por Ediciones El Almendro en 1988.
} 
sefardíes - la de sus analogías ¿y vínculos? con la poesía de pliegos de cordel hispánica- es perfectamente trasferible al terreno del análisis filológico. Hay que advertir, sin embargo, que hacer un ejercicio de comparatismo con la tradición hispánica implica una abierta parcialidad, incluso un criterio fuertemente discriminador, en el acercamiento al género, que es, en comparación con el cancionero y el romancero, el menos hispánico y más judío y sefardí de los tres grandes repertorios poéticos sefardíes. Pero también es cierto que una de las mayores ventajas que ofrece la fijación del género, la caracterización global y la profunda atención a lo judío que ya se ha realizado en las publicaciones antedichas, es la de que dejan abierta la posibilidad de análisis parciales y sectoriales de este tipo.

Sin desmerecer de su fundamental componente - temas, ideología, rasgos léxicos y estilísticos - acendradamente judío y sefardí, los mismos textos de la Selección refuerzan la impresión de que el género coplesco es también muy difícilmente comprensible fuera del contexto hispánico. No sólo por el hecho obvio de que sea hispánica la lengua sefardí que da sustento a las coplas, sino también por fenómenos como el que ejemplifica el $\mathrm{n}^{\mathrm{o}} 2$ del libro, La caída del hombre, que deriva genéticamente de un poema escrito en castellano por un judío y documentado en la Edad Media hispana; o por el hecho de que aspectos tan importantes como el métrico - basado mayoritariamente en esquemas estróficos desarrollados a partir de modelos cejelescos-, o como la rima - relacionada con el homoioteleuton de alguna poesía hispana medieval-, no puedan considerarse fuera del marco de sus paralelos peninsulares ${ }^{3}$. La acotación de la relación entre las coplas sefardíes y el género de los pliegos sueltos o literatura de cordel panhispánica viene aconsejada, además de por la pretensión de confirmar intuiciones que pueden nacer de primeras lecturas, por el carácter inexplorado hasta ahora de esta relación, y porque nos permitirá atender a una variedad de fenómenos y de recursos comunes a las distintas ramas del tronco poético

\footnotetext{
${ }^{3}$ Estos dos aspectos concretos han sido atendidos en diversos estudios de I. Hassán y E. Romero. Además de los que se relacionan en la bibliografia de la $B A E C S$, es imprescindible el artículo de E. ROMERO «Formas estróficas de las coplas sefardíes", en F. Corriente y A. SÁenz-Babillos (eds.), Poesía estrófica: Actas del Primer Congreso Internacional sobre poesía estrófica árabe y hebrea y sus paralelos romances, Madrid 1991, 259-278. Véase además una exposición actualizada en E. ROMERO, La creación literaria en lengua sefardí, Madrid 1992, págs. 141- 176.
} 
panhispánico que se hallan bien representados en títulos diversos de la Selección.

\section{LA DENOMINACIÓN DE LAS COPLAS}

La primera coincidencia significativa entre el género de las coplas sefardíes y el de la poesía de cordel panhispánica asoma en sus mismas denominaciones y en sus formatos editoriales más comunes. Porque el de coplas es justamente el título que llevaban muchos poemas conservados en pliegos sueltos antiguos españoles («Coplas agora nueuamente hechas...", "Coplas de vnos disparates...", "Coplas de unos tres pastores..."), y la denominación que el pueblo ha seguido dando preferentemente a los pliegos y pequeños folletos con cantos narrativos - nadie en los pueblos dice "pliegos" sino "coplas"- que los ciegos han seguido vendiendo hasta hace pocas décadas por ferias, calles y plazas. En la Península e Hispanoamérica se denomina a veces copla o coplilla, por extensión o analogía, a cualquier canción lírica oral y breve ${ }^{4}$, pero para todo informante -y colector - folclórico mínimamente conocedor de la tradición, "copla» designará preferentemente al poema largo e incluso al soporte papelero del pliego o folleto de cordel, mientras que la canción lírica puramente oral puede ser tan copla como coplilla, canción, etc. Aunque no es éste el lugar más adecuado para trazar una completa historia del vocablo, sí se puede recordar que desde su primera documentación hispanorromance, la cobra gallega y portuguesa, la cobla catalana y occitana y la copla castellana medieval - de arte menor y mayor- designaban preferentemente, y así ha quedado reflejado desde los tempranos tratados de poética trovadoresca hasta los tardíos cancioneros pre y renacentistas, a la estrofa que algún poeta culto ideaba desde las técnicas de la escritura -aunque muchas veces la destinase al canto- y engarzaba artísticamente en un conjunto que ocasionalmente pasaba a denominarse coblas o coplas en plural. Cabe recordar, por ejemplo, que en el

\footnotetext{
${ }^{4}$ Véase por ejemplo la definición de Margit Frenk: “llamamos coplas a las estrofas de cuatro, cinco o seis versos generalmente octosílabos que, como unidades autónomas, se van cantando con la música de los sones y otros tipos de canciones básicamente líricas», en M. Frenk, Charla de pájaros o las aves en la poesía folklórica mexicana: Discurso de ingreso a la Academia Mexicana leldo el 23 de noviembre de 1993, México D.F. 1994, pág. 10.
} 
"Arte de trovar" que abre el Cancioneiro da Biblioteca Nacional galaico-portugués, queda bien de manifiesto que cobra era un término técnico poético equivalente a estrofa:

se elles falam na prima cobra e elas na outra [he cantiga d] amor ..., e se elas falam na primeira cobra he outrosy d amigo.

En el mismo tratado, la composición completa recibía el nombre de cantiga si era de autor culto y cantiga de vilãos si era tradicional s. En la Castilla del Marqués de Santillana, copla seguía equivaliendo a estrofa culta, mientras que cantar - y otras denominaciones particulares como epithalamias, endechas, etc.- se reservaba para las composiciones tradicionales completas:

Ínfimos son aquellos $q(u e)$ syn ningu(n)d orden, regla nin cuento fazen estos roma(n)çes e cantares de que las gentes de baxa e seruil condiçió(n) se alegra(n) ... Los catalanes, valençianos e aun algunos del Reyno de Aragón fuero(n) e son grandes ofiçiales desta arte. Escriuieron primerame(n)te en nouas rimadas, $q(u e)$ son pies o bordones largos de sýlabas, e algunos consonaua(n) e otros no(n). Después desto vsaro(n) el dezir en coplas de diez sýlabas, a la manera de los lemosís ${ }^{6}$.

En la transición del siglo XV al XVI, la voz copla seguía asociándose a la creación culta y a la transmisión escrita, mientras que otros términos como canción, cantar, vilancete, villancico, etc. se reservaban preferentemente para la poesía de raíz más folclórica. La acepción copla 'estrofa culta y escrita' está documentada en las abundantes composiciones de los cancioneros cortesanos que llevan este título. Vicente Beltrán ha señalado que «Coplas era el término con que se designaba a fines del siglo XV un género poético destinado a la lectura, de cierta amplitud y ambiciones literarias" '; el Cancionero de Juan Fernández de Íxar tiene una composición titulada Respuesta de don Joan de Mendoça echando la culpa d'esta copla a dos criados del Almirante que ell uno escriuia muy bien y ell otro

${ }^{5}$ E. Paxeco Machado - J. P. Machado (eds.), Cancioneiro da Biblioteca Nacional (Antigo Colocci-Brancutti), Lisboa [1949], I, pág. 15.

6 A. Gómez Moreno, El "Prohemio e Carta» del Marqués de Santillana y la teorla literaria del s. $X V$, Barcelona 1990, págs. 57-59.

7 V. Beltrán (ed.), Jorge Manrique: Poesía, Barcelona 1993, pág. 148. 
trobaua mejor, donde desde el título hasta algunos versos interiores, quedaba claro que copla era el poema de autor que circulaba por escrito, aunque se destinara al canto:

De la copla que me toca

no es vuestro mas del papel

quereys llegar con papel

do no alcançays con la mano ${ }^{8}$.

En el Aliuio de Caminantes de Juan de Timoneda, el comentario que precede a un poema confirma lo anterior:

Estando vn poeta mostrando ciertas coplas a vn otro amigo suyo y gra[n] dezidor vino a leer vn verso que dezia ansí... ?.

Por la misma época comienzan a imprimirse muchas canciones tradicionales precedidas de la denominación Coplas - por ejemplo, "Coplas hechas de Guardame mis vacas"- ${ }^{10}$, seguramente porque el soporte del pliego las equiparaba editorialmente a las coplas cultas que desde tiempo antes se imprimían. Puede que por esta razón, a partir de mediados del XVI, la voz coplas empezase a usarse cada vez más también como sinónimo de canción popular. En un barroco e inédito Baile de èl Carreteiro, se repite varias veces, cantada por carreteros, la estrofa

Bolbamonos à la Aldèa que ya anocheziendo viene, iremos echando Copras cada qual, como Supiere,

acompañada de una retahíla de cuartetas absolutamente tradicionales ". En el siglo XVIII se amplía la doble acepción 'culta' 'popular'

8 J. M." AzÁCETA (ed.), Cancionero de Juan Fernández de Ixar, Madrid 1956, II, pág. 818 , vs. $1-2$ y $19-20$.

9 J. DE Timoneda, Aliuio de Caminantes, Alcalá de Henares 1576, f. LVIIr.

${ }^{10}$ Véanse éste y otros títulos relacionados en el Índice de M. FrENK, Corpus de la antigua lírica popular hispánica (Siglos XV a XVII), Madrid 1987, pág. 1175.

$"$ El Baile está anotado en el Ms. 16292 de la Biblioteca Nacional de Madrid (Sainetes de los dos mexores Yngenios de España...) págs. 196-199. 
del término; lo ejemplifican, por ejemplo las "Coplas do Bandarra" cultas y derivadas de pliegos que se difundieron por escrito $\mathrm{y}$ oralmente en Portugal desde el siglo XVI al XVIII ${ }^{12}$; y, frente a ellas, los párrafos en que el Padre Sarmiento afirma que

en Castilla, como en Portugal, y en otras Provincias, los hombres son los que componen las coplas, é inventan los tonos, ó ayres; y así se vé que en este género de coplas populares, hablan los hombres con las mugeres, ó para amarlas, ó para satyrizarlas. En Galicia es al contrario. En la mayor parte de las coplas Gallegas, hablan las mugeres con los hombres; y es porque ellas son las que componen las coplas, sin artificio alguno ${ }^{13}$.

A partir de ese siglo, y como ya he señalado, copla ha seguido teniendo como acepción principal la de 'pliego impreso', pero ampliando también la tardía de 'canción tradicional':

\author{
En el Vallelajara, \\ los naranjeros, \\ se acompañan las coplas \\ con el caldero ${ }^{14}$.
}

\title{
EL FORMATO EDITORIAL DE LAS COPLAS
}

Las cuestiones de la denominación y del formato editorial de las coplas están estrechamente relacionadas. De cualquier somero repaso de la $B A E C S$ se deduce que la gran mayoría de las coplas sefardíes fueron impresas en pequeños pliegos, folletos o librillos - cuyo título suele empezar por Coplas... - que quedan por debajo de las «32 planas» que Rodríguez Moñino fijó como límite de la categoría del pliego de coplas español ${ }^{15}$. En consecuencia, se puede señalar

12 A. M. Mourinho, "Coplas do Bandarra" de um manuscrito do sec. XVIII", Revista Lusitana nueva serie 1 (1981) 57-69.

${ }^{13}$ M. Sarmiento, Memorias para la Historia de la poesía y poetas españoles, Madrid 1775, pág. 238.

14 G. M." Vergara y MARTín, Cosas raras o curiosas de algunas localidades españolas según los cantares y frases populares, Madrid 1919, pág. 24.

${ }^{15}$ A. Rodríguez MoÑIno, Diccionario bibliográfico de pliegos sueltos poéticos (Siglo XVI), Madrid 1970, pág. 11: «Por pliego suelto se entiende, en general, un cuaderno de pocas hojas destinado a propagar textos literarios o históricos entre la 
que, cuando Iacob M. Hassán decía que «obligadamente tenemos que partir de una definición casi tautológica: coplas sefardíes son ... aquellos textos poéticos que los sefardíes han denominado tradicionalmente "coplas" y -añadimos- aquéllos otros que así hubieran debido denominar" ${ }^{16}$, podía haber continuado: "y que además se publicaban comúnmente en un formato editorial de pliego o pequeño folleto impreso de tipo similar al de los pliegos o folletos españoles que contenían igualmente coplas».

Parece clara la influencia homonímica y editorial de las coplas que se transmitían en pliegos impresos en el mundo hispanocristiano sobre las que de modo similar se difundían en la dispersión sefardí, aunque más difícil resulta establecer si ese trasplante poético - de denominación y formato- se produjo antes o después de la expulsión de 1492; la influencia debió de nacer y prolongarse, probablemente, antes y después de tal fecha, puesto que la comunicación demográfica y cultural entre el solar hispano y el exilio sefardí se mantuvo viva hasta bastante después de la expulsión.

Pero ya hemos avanzado que la cuestión no se queda en una simple aunque significativa coincidencia de las denominaciones castizas y de los formatos editoriales más representativos de ambos géneros en el mundo sefardí y en el hispanocristiano. El que la lectura de coplas sefardíes suela conllevar el recuerdo automático de las coplas que durante siglos han llenado los pliegos sueltos españoles tiene mucho que ver también con dos hechos muy característicos de ambos repertorios: su carácter narrativo, que condiciona la extensión -muy superior a la de las simples canciones líricas y también, normalmente, a la de los romances tradicionales-; y su naturaleza

gran masa lectora, principalmente popular. Su extensión varía según la de la obra que contienen y así, aunque en principio sirvió como norma atenerse a lo que era en verdad un pliego, es decir, una hoja de papel en su tamaño natural, doblada dos veces para formar ocho páginas, poco a poco se ha ido extendiendo el concepto y se considera como pliego suelto al cuaderno de hasta 32 planas y aún más". María Cruz García de Enterría ha preferido delimitar el número de páginas precisas para formar un pliego suelto a los "cuadernillos de 2 a 16 hojas, y también las hojas volantes impresas por un solo lado o los dos": M.' C. García DE ENTERrí, Sociedad y poesía de cordel en el Barroco, Madrid 1973, pág. 61. Joaquín Marco prefiere, por su parte, "admitir para los pliegos de los siglos XVIII y XIX la definición de Rodríguez Moñino": J. MARCo, Literatura popular en España en los siglos XVIII y XIX (una aproximación a los pliegos de cordel), Madrid 1977, I, pág. 33.

16 I. M. Hassán, "Un género castizo sefardí: las coplas", en P. Díaz-Mas (ed.), Los sefardies: cultura y literatura, San Sebastián 1987, 103-123, 106-107. 
de poesía pensada y elaborada desde y con las técnicas de la escritura -aunque después se pueda cantar y oralizar-, lo que condiciona en buena medida su estilo y usos retóricos de carácter predominantemente artificioso. Es difícil concretar en ejemplos paralelos, evidentes y unívocos, puesto que no se conocen coplas sefardíes con correspondencias textuales en pliegos españoles, lo que es más bien un aire de familia detectable únicamente por el olfato poético del lector avezado en ambos repertorios coplescos. Centrémonos, por tanto, en el análisis puntual de algún recurso de uso común que nos permita ir estrechando el círculo de sus relaciones. $\mathrm{Y}$ empecemos por el acróstico, en que puede ciertamente resumirse buena parte de la cuestión de orígenes, influencias y correspondencias del género.

\section{El ACRÓSTICO SEFARDÍ Y EL ACRÓSTICO HISPÁNICO}

El acróstico es un recurso poético muy característico de la poesía hebrea desde la Biblia hasta la Edad Media ${ }^{17}$. Aparece además en la poesía medieval en castellano escrita presumiblemente por judíos, como en el planto jAy Iherusalem! o en la Lamentación del alma ante la muerte ${ }^{18}$. Precedentes que podrían parecer aval suficiente para considerar los característicos acrósticos de las coplas sefardíes como continuadores de los hebreos y de los hispanojudíos viejos. Sin embargo, y aunque no exista un estudio de conjunto ni se haya prestado antes la suficiente atención al fenómeno, no se puede olvidar que el acróstico es un recurso también muy difundido en

17 Véanse al respecto las páginas que le dedicaron J. M.* Millás Vallicrosa, "La tradición del estrofismo bíblico en las poesías medievales", Sefarad I (1941) 4587, 49 y 57-58; e IDEM, La poesía sagrada hebraicoespañola, Madrid 1940, págs. 60 y 63; y D. Gonzalo MAESo, "Algunos aspectos de la poesía sinagogal", MEAH III (1954) 5-22.

18 Sobre el primero, véase especialmente - porque atiende de manera muy particular a su estructura métrica- el estudio de H. DE VRIES, "Un conjunto estructural: el Poema tríptico del nombre de Dios en la ley", BRAE LI (1971) 305-325. Sobre el segundo, véanse J. A. CID, "Lamentación del alma ante la muerte: un nuevo poema medieval judeo-español. Ensayo de edición", en F. Corriente - A. SÁenz-Badillos, Poesía estrófica, 43-70; IDEM, "Lamentación del alma ante la muerte: nuevo poema medieval", en B. Garza Cuarón - Y. Jiménez de Báez [B. Mariscal - A. GoNZÁLEZ] (eds. [y comps.]), Estudios de folklore y literatura dedicados a Mercedes Díaz Roig, México 1992, 729-791, especialmente 736, 763-764 y 791. 
otras tradiciones literarias universales ${ }^{19}$, incluidas otras ramas de la hispánica. Se puede rastrear, por ejemplo, en obras tan variadas como la producción poética cancioneril de Manrique, Villasandino, Cartagena, Enrique da Mota o Juan del Encina ${ }^{20}$, en La Celestina ${ }^{21}$ o en el Cancionero de Herberay des Essarts ${ }^{22}$, pasando por el soneto y el romance renacentista y barroco ${ }^{23}$, el teatro áureo ${ }^{24}$ o la poesía

${ }^{19}$ Sobre el uso del acróstico en literaturas extrahispánicas, véase F. DornSEIFF, Das Alphabet in Mystic und Magie, Berlín 1922; M." R. LidA DE MAlkiel, La originalidad artística de La Celestina, Buenos Aires $1970^{2}$ págs. 15-16; y I. y P. OPIE, The Oxford Dictionary of Nursery Rhymes, Oxford 1975, nos 1-5.

${ }^{20} \mathrm{P}$. LE GENTIL, La poésie lyrique espagnole et portugaise à la fin du Moyen Âge, Rennes 1949-1952, I, págs. 189-192, y II, pág. 135.

${ }^{21}$ M.2 R. Lida DE MALKIEl, La originalidad, págs. 15-16.

${ }^{22}$ M." GoYri de Menéndez Pidal, "Dos notas para El Quijote", RFE II (1915) 33-40; y $\mathrm{CH}$. V. Aubrun, Le chansonnier espagnol d'Herberay des Essarts, Burdeos 1951, págs. 188-196.

${ }^{23}$ Uno de los más activos usuarios renacenistas de esta técnica fue el catalán Pere Serafi, que dedicó poemas acrósticos a numerosas damas. Cfr. al respecto "Poemes en castellà atribuïbles a Pere Serafi", y "Les dames cantades per Pere Serafi en els seus poemes catalans", en J. Romeu I Figueras, Poesia en el context cultural del segle XVI al XVIII, Barcelona 1991, I, págs. 138-221 y 222-251. En el Ms. 8754 de la Biblioteca Nacional de Madrid [Coplas de Asuntos Varios] ff. 3r-6v, está anotado un "Romance acróstico endecasílabo" barroco cuyas iniciales de verso revelan que es “ $D$ ' Antonia Cavallo profesa en el Colegio de las Virgynes de Zaragoza». D. Gaspar Avgustin de Lara, en el folleto Parangon de la fe de Avstria... [B.N.M. VC" 128-40] f. 13rv, incluye un "Soneto Acrostico al glorioso nombre del rey N. S. Carlos de Avstria" y un "Labirinthvs chronologicvs, cum Acrosticis" que permite leer en latín "Carolvs Rex Ibervs Sacramenti Servvus». En F. BuENo, Epitalamio en las felizes bodas del señor D. Fadrique de Silva ... con la Señora Doña Juana de Silva..., Madrid 1688, [B.N.M. VC" 128-19] f. 2v, hay un "Soneto Acróstico" que forma los dos nombres de "Juana y Fadrique" con las letras iniciales de cada verso. Especial interés tienen los abundantísimos pliegos que lamentaron la muerte de la reina María Luisa de Borbón, entre los que había muchos que utilizaban el recurso del acróstico: Romance Acrostico Endecasylabo a la mverte de la Reyna Nvestra Señora doña Maria Lvisa de Borbon, Reyna de España [B.N.M. Ca 24-21]; Vizconde de San Miguel y de Otero, Soneto Acróstico a la mverte de la Reyna nvestra Señora Doña Maria Lvisa de Borbon [B.N.M. Ca 24-20]; Don Jvan Casimiro de Velasco Vizcaino, Al tan sentido quanto lamentable fallecimiento de la reyna... [B.N.M. C" 68-91]; Al riguroso dolor que causo en lo mayor de los qvatro elementos la muerte de la Reina Nvestra Señora... [B.N.M. C' 24-40]; Don Ioseph Ogazon Angulo, Al lamentable fallecimiento de la magestvosa y florida primavera... [B.N.M. C* 24-39]. Reproducen o citan sonetos barrocos acrósticos M. ARTIGAS, en el "Catálogo de los manuscritos de la Biblioteca (continuación)", Boletín de la Biblioteca de Menéndez Pelayo XI (1929) 168-188, 170; A. HuARTE, en "Papeles festivos del reinado de Felipe IV: III", Revista de Archivos, Bibliotecas y Museos LI (1930) 441-460, 450; y M. Concha, Tradiciones serenenses, Santiago de Chile 1975, II, pág. 18 (un poema acróstico a Felipe V).

${ }^{24} \mathrm{El}$ acróstico está presente en obras de teatro barroco, como sucede en el "abecé" cantado por el protagonista de Peribánez y el comendador de Ocaña (I:IX) 
llamada visual ${ }^{25}$, hasta llegar a la poesía báquica, política, etc., más moderna ${ }^{26}$.

Aunque, como acabamos de advertir, se trata de un recurso complejo y universal, al menos en épocas literarias modernas el acróstico se ha asociado estrechamente a la poesía de pliegos de cordel. Poemas de asunto satírico, amoroso, noticiero, religioso, etc., con acróstico, han circulado y circulan hasta hoy mismo en pliegos sueltos, y algunos incluso se han popularizado o tradicionalizado en España, Portugal o Hispanoamérica ${ }^{27}$. En la tradición

de Lope de Vega, o en la anónima Loa famosa de las letras ABC editada en E. Cotarelo y MORI, Colección de entremeses, loas, bailes, jácaras y mojigangas, Madrid 1911 [NBAE XVII y XVIII], II, $\mathrm{n}^{\circ} 138$.

${ }^{25}$ Pueden leerse - $-\mathrm{y}$ verse- numerosos y extravagantes poemas acrósticos en $\mathrm{J}$. M. ${ }^{a}$ DíEz Borque (ed.), Verso e imagen: del Barroco al Siglo de las Luces, Madrid 1993, págs. 29-72.

${ }^{26}$ Ejemplos de poemas acrósticos de contenido político pueden ser, por ejemplo, el Acróstico prosaico bufo de los partidos políticos de España al que se refiere E. CASARES Rodicio, "El teatro de los bufos o una crisis en el teatro lírico del XIX español", Anuario Musical 48 (1993) 217-228, 225; o el que en la España de comienzos del siglo XX satirizaba a la dictadura de Primo de Rivera permitiendo leer "Primo es borracho" con la letra inicial de cada verso (cfr. M. BARRIOS, Rimas de la oposición popular, Madrid 1975, pág. 45). Un ejemplo de acróstico en una composición báquica es la de Hippolyte Fostin que, en la Francia decimonónica, identificaba mediante este recurso al destinatario del poema, Jules Janin (cfr. $\mathrm{CH}$. Coligny, La chanson française: histoire de la chanson et du caveau, París 1876, pág. 299).

${ }^{27}$ Yo he llegado a ver, en numerosos pliegos encontrados en librerías de viejo, series de aleluyas, a menudo ilustradas con dibujos, que relataban todo tipo de anécdotas siguiendo el orden de las letras del alfabeto. Un precioso ejemplo extrahispánico de este tipo de composiciones es el Alfabeto del villano en veintitrés estrofas ilustradas que se vendía en el siglo pasado por calles y plazas italianas y que publicó P. MEYER, "Dits sur les vilains par Matanzone de Calignano", Romania XII (1883) 1428. Composiciones de tipo similar son descritas en P. Vitorino, "Alfabetes figurados", Douro Litoral VIII (1943) 28-33. Por otro lado, abecedarios de enamorados popularizados o tradicionalizados han sido publicados en J. A. CARrizo, Cancionero popular de Tucumán, Buenos Aires - México 1937, vol. II, págs. 31-32; R. CANTEL, "Survivances modernes de la littérature populaire au Portugal", en Hommage à Amédée Mas, París 1972, págs. 19-28, 26-27; J. LeITE DE VASCONCEllos, Cancioneiro popular português, (ed. M. A. Zaluar Nunes, Coimbra 1975-1983, I, págs. 334-338); L. DA Camara Cascudo, Literatura oral no Brasil, Río de Janeiro 19782, págs. 367-369; M. Da Costa FonTes, Romanceiro da Província de Trás-os-Montes, Coimbra 1987, II, pág. 1196; e I. Fonseca dos Santos - M. F. Barbosa de Mesquita Batista, Cancioneiro de Paraiba, Paraíba 1993, págs. 236-237. En las obras citadas de Cascudo y de Santos y Mesquita (págs. 278-279 y 323) se extractan también poemas acrósticos populares de temática noticiera, costumbrista o religiosa. Composiciones acrósticas sobre otros temas, como vidas de bandoleros, son citadas en L. DA CAMARA CasCuDo, "Da poesia popular narrativa no Brasil", en 25 Estudios de Folklore: Homenaje a Vicente T. Mendoza y Virginia Rodríguez Rivera, México 1971, págs. 151-166, 157-153. Referencias a "obscene alphabets" anglosajones se pueden encontrar, finalmente, en G. Legman, "Bawdy Monologues and Rhymed Recitations", Southern Folklore Quarterly 40 (1976) 59-122, 92. 
sefardí son bastante comunes las coplas con acróstico alfabético -o mejor dicho, alefático-, aunque tampoco son desconocidas las que muestran acróstico onomástico. Algo parecido sucede en el conjunto de la tradición hispánica, donde un repertorio en el que parece haber calado el acróstico alfabético, y donde más similitudes muestra con el que desarrollan las coplas sefardíes, es el de la poesía cristiana edificante, hasta el punto de poder hablarse de un - muy desatendido- subgénero de «abecedarios espirituales" renacentistas y barro$\cos { }^{28}$, que parece ser un claro precedente de muchas composiciones del mismo tipo que se han conservado en la tradición oral española. Yo mismo he recogido, en pueblos como Mogarraz y Villavieja de Yeltes (Salamanca) o Casares de Arbas (León), largas composiciones poéticas que desgranan en cuartetas cantadas con acróstico alfabético la Pasión de Cristo entreverada de altisonantes lecciones morales y religiosas para los fieles. Según los datos que alcancé a recoger de mis informantes, tales "abecedarios" a lo divino circulaban en hojillas o pliegos impresos o manuscritos que facilitaban su canto dentro de la iglesia en las celebraciones de Cuaresma y Semana Santa; aunque lo cierto es que muchos feligreses, como era el caso de mis informantes -algunos analfabetos-, se sabían todas las estrofas de memoria y, con el apoyo mnemotécnico del acróstico, podían prescindir de los pliegos escritos. Del arraigo panhispánico de este tipo de composiciones da fe el hecho de que se hayan documentado en lugares como Argentina o Brasil ${ }^{24}$. Pilar García de Diego, al editar un "Divino abecedario" y luego un "Abecedario de la Pasión" de este tipo, advertía cautamente que «este abecedario de indudable

${ }^{28}$ Puede consultarse, sobre ellos, Fray Miguel Ángel, "La vie franciscaine en Espagne entre les deux couronnements de Charles Quint: IV", RABM XXIX (1913) 163 ; «... V», 157-216; y “... VI», RABM XXX (1914) 1-62. Otros abecedarios espirituales inéditos que conozco son, por ejemplo, las 23 octavas reales que conforman "El ABC a la concepción de Nuestra Señora" anotado en el Parnasso Christiano de Pedro de Liébana (1678) [Manuscrito 3674 de la B.N.M.] ff. 71-78; o “Del abecedario todas las letras..." de tema navideño anotado en el Manuscrito 3798 de Romances consagrados a Dios ... y a María Santísima (1639) de la misma biblioteca, ff. 52v-53v. Este tipo de poemas debió de estar tan presente en la vida espiritual del Renacimiento como para inspirar obras mayores en prosa, del tipo del Alfabeto cristiano publicado en italiano en 1546 por Juan de Valdés; además, su arraigo e influencia acaso alcanzó a otras artes, como sugiere, por ejemplo, la serie de grabados de El alfabeto de la muerte de Hans Holbein.

${ }^{29}$ Cfr., por ejemplo, el "Acróstico sobre Cristo" editado en J. A. Carrizo, Cancionero popular de Jujuy, Tucumán 1935, págs. 145-146; y alguno religioso al que se alude o se extracta en L. DA CAMARA CASCUDO, Literatura oral, págs. 367-369. 
origen culto, hecho probablemente por algún sacerdote en el final del siglo XVII ... pasó a la tradición oral» ${ }^{30}$. La observación viene muy a cuento, porque simplemente cambiando la palabra "sacerdote» por "rabino" o "autor letrado", ampliando el ámbito temporal también a los siglos posteriores, y trasladándonos a las comunidades sefardíes del Oriente mediterráneo, obtenemos el perfil típico de autoría culta, intención devota, admonitoria y moralizadora, ocasionalidad paralitúrgica y método compositivo y evolutivo que va de la escritura a la oralidad característicos de muchas coplas acrósticas sefardíes. Las cuales - recordemos- fueron compuestas por autores letrados, en algunos casos rabinos, que las solían dar al canto coral acompañante de festividades y ritos paralitúrgicos, lo que facilitaba la memorización ocasional $\mathrm{y}$, en algún momento, el que fuesen afectadas por fenómenos de cambio oral e incipiente tradicionalización que explican las variantes detectadas entre testimonios y fuentes diversos.

El acróstico onomástico aparece también en algunas coplas sefardíes compuestas entre los siglos XVIII y XX, rasgo en el que vuelve a coincidir con la tradición panhispánica. Las coincidencias que en este punto pueden llegar a detectarse entre las coplas judeoespañolas y, por ejemplo, la poesía de cordel brasileña, son muy llamativas. Así, si nos fijamos en la copla no 14 de la Selección de Elena Romero (BAECS 189b), la titulada Penuria en casa de Yacacob Yoná, comprobaremos que, sobre sus ocho cuartetos monorrimos, aparece el nombre del autor Ya'acob Yoná, quien se lamenta en el poema de sus penurias económicas, y anima, con gracia e ironía, a la compra de sus coplas y a la colaboración en el difícil mantenimiento de sus hijas por casar. Es cierto que la consignación en acróstico del nombre del autor no es un recurso desconocido entre los juglares de otros tiempos y latitudes; casos similares pueden encontrarse desde el medieval Roman de Fortune francés, cuyo autor, Simon de Freine, se identificaba así al inicio de su obra ${ }^{31}$, hasta el más famoso trovero improvisador vivo de Murcia, El Repuntín, que gusta de presentarse de la mismo forma ${ }^{32}$. Pero donde el recurso está verdaderamente arraigado es justamente en la poesía de cordel

${ }^{30}$ P. Garcta DE Diego, “Devociones populares", Revista de Dialectología y Tradiciones Populares VI (1950) 315-327, 320.

${ }^{31}$ P. MeYer, «Notice et extraits du Ms. 8336 de la Bibliothèque de Sir Thomas Phillips à Cheltenham", Romania XIII (1884) 497-541, 533.

32 Cfr. la décima acróstica editada en M. LuEngo LóPEz, José Travel Montoya, El Repuntín: trovero, Murcia 1984, pág. 19. 
brasileña, en la que la defensa mediante el acróstico onomástico de los derechos y necesidades económicos del autor, tan apretado siempre de dinero como el Ya‘acob Yoná de Salónica, cuenta con larga tradición. Los párrafos que ha dedicado Candace Slater a esta curiosa forma de copyright acróstico para evitar que copleros y juglares rivales se apropien de la composición son reveladores:

Los acrósticos son comunes en la literatura de cordel debido a los constantes problemas que hay con los derechos de propiedad. Aunque pueden ser fácilmente «borrados" por cualquier poeta que intente hacer pasar una composición como suya, un buen porcentaje de folhetos que llevan sólo el nombre del editor en la cubierta, muestran estrofas conclusivas inalteradas. En el caso de El rey, la paloma y el gavilán, no sólo aparece este normal elemento identificatorio, sino también un acróstico interno ampliado. Las letras iniciales de la primera línea de las primeras veintidós estrofas dejan leer: «AUTOR JOSE DE SOUZA CAMPOS"... Aunque el poeta hilvana un acróstico identificador final como precaución contra los piratas literarios, no es difícil para otros colegas reorganizar las letras iniciales de la última estrofa, borrando de ese modo el nombre original ${ }^{33}$.

LAS COPLAS DE DESASTRES NATURALES: TRADICIÓN SEFARDí Y TRADICIÓN HISPÁNICA

La coincidencia en la denominación -o autodenominación- de coplas, en el formato editorial habitual, en el carácter esencialmente narrativo, en los recursos propios de la escritura, en el estilo artificioso, o en aspectos formales tan característicos como el uso del acróstico alfabético u onomástico, nos permite ir avanzando, al menos en los terrenos formal y estilístico, que no pueden ser casuales las similitudes que se aprecian entre los géneros coplísticos sefardí y panhispánico. La exploración de algún otro recurso común más - ahora no formal, sino temático - puede que abra nuevas perspectivas a la cuestión.

Lo haremos a partir de la copla $\mathrm{n}^{0} 13$ de la Selección de Elena Romero (BAECS 183a): la de Los terremotos de 1902, compuesta por el coplero salonicense Yacacob Yoná y que comienza "Oíd mis hermanos / este muevo cante...". No es ésta la única copla sefardí

${ }^{33}$ Traduzco de C. Slater, Stories on a string: the Brazilian "Literatura de Cordel", Berkeley - Los Ángeles - Londres 1982, págs. 95 y 26. 
que aborda el asunto de los terremotos. Se conocen una versión oral de El terremoto de Estambul de 1884 que comienza "En año de šečentos / y cuarenta y cuatro...", y otra también oral acerca de otro terremoto sin identificar, que no comienza por ninguna concreción de fecha, sino por los versos «Este día terrible / non cale olvidarvos..." ${ }^{34}$. También existe un variado repertorio de coplas sefardíes relacionadas con desastres de tipo parecido, particularmente incendios: El fuego de 1890 (BAECS 151ac); El socorro a los quemados de 1890 (BAECS 148a) que comienza «En dieź y mueve elul / šečentos y cincuenta..."; Los daños del fuego de 1908 (BAECS 194a) que comienza "En año de šečentos / y sesenta y ocho..."; El fuego y las lluvias de 1908 (BAECS 195a) que comienza "Año de šečentos / y sesenta y ocho..."; El incendio de 1921, que comienza "En año de šečentos / y ochenta y uno..." ${ }^{35}$; y diversas coplas —el detalle no es exhaustivo- sobre El pedrisco de 1899, [La aparición de] el cometa, La crisis de 1913 - que comienza "Añada de setenta y tres y de cuatro mos trujo criśa..." o El fuego de 1917, estampadas todas éstas por ese mitad poeta y mitad cronista de sucesos que fue Yoná (BAECS 173a-d, 208a, 217b, 221a-b).

Es asombroso advertir que, al igual que sucede en el ámbito sefardí, la tradición panhispánica de la literatura de cordel se ha fijado en los terremotos y en otros desastres naturales de manera casi obsesiva. María Cruz García de Enterría, en su ya clásico libro Sociedad y poesía de cordel en el Barroco ${ }^{36}$, ha dedicado todo un revelador capítulo (en págs. 217-223) a los pliegos antiguos que se refieren a "Fenómenos climatológicos y catástrofes naturales», fijando especialmente su atención en los pliegos sobre los terremotos de la isla Tercera (Azores) y de Granada de 1614. Un catálogo de pliegos de cordel del siglo XVIII editado por Francisco Aguilar Piñal da referencias de pliegos sobre los terremotos de Roma, Madrid, Sevilla, Salamanca, Cádiz, Lisboa, Huelva, Córdoba, Orán, Moguer, Asculi (Italia) y Sanlúcar de Barrameda ${ }^{37}$. Otro catálogo de pliegos del siglo XIX de $\mathbf{M}^{\mathrm{a}}$ Carmen Azaustre Serrano da fe de cantos sobre los

${ }^{34}$ Ambas versiones pertenecen al archivo folclórico (Proyekto Folklor) de la Radiodifusión israelí, cuya copia está en la biblioteca y archivo de Estudios Sefardíes del CSIC de Madrid. La primera copla (PF 080/11) fue cantada por Mazal Politi, nacida en Estambul en 1920. La segunda (PF 188/08), por Uriel Mizrahi, nacido en Turquía en 1910.

${ }^{35}$ La versión pertenece al Proyekto Folklor (PF 080/12) y fue recogida también a la señora Mazal Politi.

36 Publicado en Madrid por Taurus en 1973.

37 F. Aguilar Piñal, Romancero popular del siglo XVIII [Cuadernos Bibliográficos XXVII], Madrid 1972, n 141 (Roma); n 219 y 246 (Madrid); nos 242, 244-245, 248- 
terremotos de Orihuela, Murcia, Noguera, Santiago de Cuba, Sicilia, Nápoles, Manila y Andalucía ${ }^{38}$. El terremoto de Orihuela de 1829, especialmente, desató una intensa producción de pliegos -amén de alguna novela folletinesca - que describían con sobrecargadas tintas su violencia ${ }^{39}$. Algún poema de autor culto pero claramente influido por la retórica de los pliegos de cordel nos ha llegado sobre el terremoto de Salamanca de fines del siglo XVIII ${ }^{40}$. Igual que, en Portugal o en Canarias, se han recogido cantos de tradición oral sobre terremotos, que muestran claras señales de proceder de pliegos escritos ${ }^{41}$.

Pero lo más sorprendente no es que la temática de los terremotos y las catástrofes naturales se haya cultivado con la misma extraordinaria vitalidad en las coplas sefardíes y en las panhispánicas ${ }^{42}$, sino que rasgos de poética tan particulares como el de las fórmulas

249 y 253 (Sevilla); n 243 (Salamanca); nos 247, 254, 256 y 259 (Cádiz); nos 250-252 (Lisboa); $n^{\circ} 255$ (Huelva); nos 257-258 (Córdoba); $n^{\circ} 260$ (Orán); $n^{\circ} 261$ (Moguer); $\mathrm{n}^{Q} 1719$ (Asculi, Italia); y n 1753 (Sanlúcar de Barrameda).

38 C. Azaustre Serrano, Canciones y romances populares impresos en Barcelona en el siglo XIX [Cuadernos Bibliográficos XLV], Madrid 1982, págs. 150-151 (Orihuela y Murcia); pág. 177 (Noguera y Orihuela); pág. 185 (Santiago de Cuba); pág. 206 (Reino de las Dos Sicilias); pág. 206 (Reino de Nápoles); pág. 238 (Manila); pág. 271 (Andalucía).

39 Véase al respecto J. MARCO, Literatura popular en España, I, págs. 336-337; y F. RODRIGUEZ DE LA TORRE, “Literatura popular sísmica: una novela y muchas poesías sobre el terremoto del 21 de marzo de 1829", Revista de Folklore 142 (1992) 111-122.

${ }^{40}$ Me refiero a la "Descripción funesta del Terremoto de Salamanca", anotado en la Colección de varias poesias inéditas serias y jocosas hecha por don Francisco Xavier de Santiago Palomares, natural de Toledo, tomo I, [Manuscrito I7646 de la B.N.M.] ff. $214 \mathrm{r}-216 \mathrm{v}$.

${ }^{41}$ Véanse en Th. Braga, Cancioneiro Popular, Coimbra 1867, III, págs. 131-132: "Romance do Terremoto de Villa Franca do Campo»; y en M. J. Lorenzo Perera, El Folklore de la Isla de El Hierro, Sta. Cruz de Tenerife 1981, págs. 167-168.

${ }^{42}$ La temática de los terremotos ha dado además pie, en el terreno de los estudios hispánicos, a artículos como los de A. MACHADo Y Álvarez, "Los terremotos y la tradición popular", Los Lunes de El Imparcial, 16-2-1885, pág. 4; R. DE MIRANDA, "Os fenómenos sísmicos na ética, nas religiões e no folclore", en Actas do $1^{\circ}$ Congresso de Etnografia e Folclore promovido pela Camara Municipal de Braga, Lisboa 1963, II, págs. 307-311; R. Calvo, "Del Folklore a la Antropología del Terremoto en el Cuzco Peruano", Folklore Americano 54 (1992) 111-116; y B. VinCENT, "La tierra tiembla en Andalucía: Estudio histórico (siglos X-XIX)", en J. A. GonZÁleZ AlCANTUd - M. GonZÁlez DE Molina (eds.), La tierra: mitos, ritos y realidades, Barcelona - Granada 1994, 441- 452. Incluso en las coplas del "rosario de la aurora" que se cantan todavía en algún pueblo español se desarrolla el tema y se pide protección contra los terremotos. Cfr. al respecto M. L. Escribano Pueo - T. Fuentes VÁZQUez - F. MOREnTE MuÑoz - A. Romero LÓPEZ, Cancionero granadino de tradición oral, Granada 1994, nos 720 y 725. 
iniciales presentadoras de la fecha del desastre estén también reiterada y característicamente presentes en ambos repertorios. Un pliego sobre el terremoto de Granada de 1614 antes aludido comenzaba: "A cinco del mes de octubre / la ciudad regocijada..." ${ }^{43}$. Sesenta años antes, un pliego gótico, que se conserva en la Biblioteca Nacional de Madrid, describía «El grande incendio de fuego de las naos que se quemaron en la ribera de Guadalquiuir de la muy noble y muy leal ciudad de Seuilla" con una precisión temporal aún mayor: "Año de cincuenta y quatro / veynte y dos era el mes / de Setiembre, un dia despues / de Sant Mateo..." ${ }^{44}$. Un pliego del XVIII también describía el terremoto de Roma de 1713 con marcas temporales precisas: "A los catorce de Enero..." ${ }^{45}$. Otro pliego de la misma época sobre un huracán que afectó a Plasencia detallaba hasta la hora: "Treinta de Setiembre, / dia de aquel Doctor, de quien vieron, / que el temor en el oido, / son desgarros en el pecho. / A las diez de la mañana / se inquieta el aire, diziendo..." "46. Sobre el terremoto del 1 de noviembre de 1755 en Madrid circuló un pliego suelto que comenzaba "Día de Todos los Santos / tembló Madrid...» ${ }^{47}$, aunque todavía más concreto fue el pliego que saludó una especie de bólido, seguramente un meteorito, que apareció en el cielo madrileño en 1896: «El día diez de febrero / a las diez de la mañana..." ${ }^{48}$. A la tradición oral canaria de hoy en día ha llegado un canto narrativo que tiene toda la apariencia de derivar de algún pliego de cordel y que recuerda un Terremoto en La Gomera en versos que empiezan: "Año de mil ochocientos que hasta el veintiséis se cuenta, / a las once de la noche, a eso de las nueve y media..." ${ }^{49}$. En la misma tradición canaria, el hundimiento del barco Valbanera dejó un recuerdo poético imborrable: «Septiembre día memorable /

${ }^{43}$ M.2 C. García de EnTerría, Sociedad y poesía de cordel, pág. 219.

44 J. García Morales (ed.), Pliegos poéticos góticos de la Biblioteca Nacional, Madrid 1957-1961, IV, págs. 201-206.

${ }^{45}$ F. Aguilar Piñal, Romancero popular del siglo XVIII, $\mathrm{n}^{\circ} 141$.

46 A. Rodríguez-MoNino, Diccionario geográfico popular de Extremadura, Madrid 1965, n 972: «Relación verdadera. Donde se declara, y da quenta del destrozo, y rvina, que padeciò la ciudad de Plasencia en treinta de setiembre, por el huracan, el qual derroto parte de la Santa Iglesia...", vs. 9-14.

47 Véase su transcripción en B. GlL, La fama de Madrid según la tradición popular, sacada de refranes, coplas, canciones, romances y leyendas de todas las regiones españolas y paises hispanoamericanos, Madrid 1958, págs. 278-279.

48 B. GIL, La fama de Madrid, págs. 279-281.

${ }^{49}$ M. Trapero, Romancero de la Isla de La Gomera, La Gomera 1987, $\mathrm{n}^{2} 356$. 
del mil nueve diecinueve..." ${ }^{50}$; como lo dejó también El temporal de la isla de La Palma ocurrido el 16 de enero de 1957: «El día dieciséis

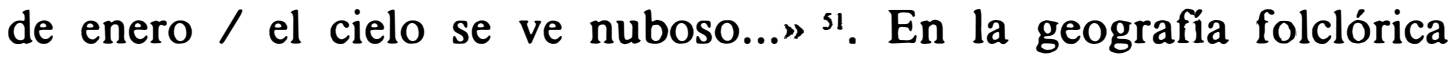
hispanoamericana no son desconocidos este tipo de composiciones y recursos, que llevaron a Luis Felipe Ramón y Rivera a titular «De flagelos naturales» uno de los apartados de su libro La poesía folklórica de Venezuela ${ }^{52}$, y a reproducir un Corrido de la creciente de El Cobre que empezaba "En noviembre veintisiete / del año cuarenta y dos / quiso castigarnos Dios / con una inmensa creciente...". La descripción poética de una gran inundación en Brasil comenzaba: "Na éra de vinte e quatro / a douze do mez de Abril / um sabbado pella manhã / veio as aguas reagir / fazendo grandes horrores / nos Estados do Brazil..." ${ }^{53}$. En el corrido mejicano son igualmente corrientes este tipo de temas catastróficos $\mathrm{y}$ fórmulas retóricas: "Agosto del sesenta y nueve: / es terrible la impresión / de tanto llueve que llueve. / Nos llegó la inundación...» ${ }^{54}$. En la ya casi extinguida tradición de los isleños de la Luisiana también se podía escuchar hace poco que «En mil novesientos quinse / estando el reló ${ }^{\circ}$ a las cuatro, / estando la gente inosente / yegó el temporal ingrato..." "ss. Y en el dominio portugués, un célebre accidente de aviación que tuvo lugar en 1934 encontró también el eco de coplas noticieras como la que empezaba "A 22 de Fevereiro / chocaram os dois avies / como dizem os jornais / nas suas informações..." ${ }^{56}$.

${ }^{50} M$. TRAPERO, “El romancero y la décima juntos y enfrentados en la tradición de Canarias", en M. TRAPERO (ed.), La décima popular en la tradición hispánica: Actas del Simposio Internacional sobre la décima, Las Palmas de Gran Canaria 1994, 141174, 167.

51 M. Pérez Rodríguez, "La décima en la emigración canario-cubana: el caso de La Palma", en M. Trapero, La décima popular, págs. 311-321, 315.

52 La obra fue editada en Caracas en 1988, y el apartado ocupa las págs. 105-110.

53 L. DA CAMARA CASCUDo, "Da poesia popular narrativa", pág. 158.

54 R. Pérez Monfort, Tlacotalpan, la Virgen de la Candelaria y los sones, México 1992, pág. 105.

s5 S. G. ARMISTEAD, The Spanish Tradition in Louisiana, I: Isleño Folkliterature, Newark 1992, pág. 14.

${ }^{56}$ M. Viegas Guerreiro - A. Machado Guerreiro, Literatura popular do distrito de Beja, Beja 1986, pág. 118. Antes de rematar esta larga lista de poemas fechados, no se puede omitir que este recurso no es propio solamente de los poemas de pliego de cordel o derivados o influidos por ellos y referentes a catástrofes naturales, sino en general de toda la poesía narrativa, especialmente de cordel, de carácter noticiero. Selecciono diversos ejemplos ilustradores de su variedad temática: sobre conflictos bélicos en las fronteras de México y Estados Unidos a comienzos de siglo circuló el corrido "En mil novecientos quince, / ¡qué días tan calurosos! / voy a contar estos 
La comunidad de temas y de recursos poéticos que se hace visible en las coplas panhispánicas y sefardíes "de terremotos" y otros desastres que acabamos de analizar, vuelve a estrechar el círculo de los vínculos e influencias que han debido de existir entre ambos dominios y géneros poéticos. A la vista de todo ello, se va reforzando la impresión de que entre las coplas de cordel panhispánicas y las coplas sefardíes hay una evidente relación nominal, editorial, formal y estilística que prueba la influencia de un género sobre el otro.

\section{LA COPLA DE LA DESTRUCCIÓN DEL TEMPLO Y EL RECURSO DEL UBI SUNT}

No sería ecuánime, sin embargo, deducir de todo esto que las coplas panhispánicas y las sefardíes fueron ramas simétricas de un mismo tronco. Tan evidentes como sus similitudes y paralelismos son sus diferencias y sus rasgos denotadores de personalidades propias y en buena medida autónomas. Como tantas veces se ha puesto de relieve, las coplas sefardíes están mucho menos enraizadas en el tronco común hispánico, y son temática e ideológicamente mucho más judías y sefardíes que el romancero y el cancionero judeoespañoles; su dependencia de los modelos panhispánicos se circunscribe

versos, / versos de los sediciosos..." (R. R. FloRES, "The Corrido and the Emergence of Texas-Mexican Social Identity", Journal of American Folklore 105:416 [1992] 166182); sobre la muerte del presidente Getulio Vargas circuló por Brasil el canto que comenzaba "Vinte quatro de Agosto / dia de Bartolomeu / dia tragico que a morte / baixou o decreto seu..." (L. DA CAMARA CASCUDo, "Da poesia popular narrativa" págs. 159-160); la dramática muerte de una madre y su hija al cruzar una nevada cumbre canaria inspiró unas décimas que comenzaban "El veinte y cinco de abril / de mil novecientos treinta, / exacta tengo la cuenta / por más que no sé escribir..." (M. Pérez Rodríguez, "La décima», pág. 315). Un desgraciado episodio amoroso dio lugar en Portugal a la composición "No dia Um de Outubro / um caso se sucedeu: / no lugar de Sargaçais / ai, Deolinda faleceu..." (M. AliETE Galhoz, "Literatura popular: cantigas narrativas", Revista Lusitana nueva serie 9 [1988] 151155); una excursión campestre de los vecinos de Medellín (Badajoz) fue recordada así por Josefa Palma, una anciana de unos 80 años, a la que entrevisté en aquel pueblo en octubre de 1988: "Año de mil novecientos veinte, / el día cinco de abril, / ha salido una excursión / del pueblo de Medellín..."; y finalmente, y para cerrar este variado muestrario de posibles temas y contextos en los que pueden aparecer las dataciones poéticas que nos han estado ocupando, una fiesta carnavalesca catalana fue descrita así poéticamente: «I avui en nit de febrer / d'aquest any quaranta-vuit, / el Drac es troba al carrer / tot amanit i ben cuit..." (N. DomEDEL, Fauna fantástica de Catalunya, Barcelona 1991, pág. 24). 
mayormente a unos pocos y abstractos rasgos formales y funcionales, mientras que el romance y la canción han heredado, además de moldes formales característicos, muchos temas y motivos genéticamente -y estrechamente- derivados del repertorio hispano. La búsqueda de fuentes poéticas de muchas coplas sefardíes nos llevaría por caminos muy complejos de los que las únicas conclusiones seguras que podríamos extraer serían, además de la de su relación formal y funcional con las coplas hispanas, la de su estrecha vinculación con el mundo ideológico y cultural judío y la de la personalidad profundamente sefardí del género. Veamos un ejemplo: en la copla no 9 de la Selección de Elena Romero, La destrucción del Templo de Jerusalén es llorada (estrofas 7 y 8 ) con estos sentidos versos:
¿Adónde están los kohanim, los que perdonaban los 'avonim con los vestidos lebanim delantre el Dio enšalžado? ¿Ánde están muestros señores que cayeron entre angustiadores, los que cantaban con sabores delantre el duján tan preciado?

La evocación de las famosísimas Coplas a la muerte de su padre de Jorge Manrique es casi automática:

¿Qué se hizo el rey don Juan?

Los infantes de Aragón, ¿qué se hizieron?

¿Qué fue de tanto galán?

¿Qué fue de tanta invención como traxieron?

¿Qué se hizieron las damas, sus tocados, sus vestidos, sus olores?

¿Qué se hizieron las llamas de los fuegos encendidos de amadores?

¿Qué se hizo aquel trobar, las músicas acordadas 
que tañían?

¿Qué se hizo aquel dançar,

y aquellas ropas chapadas

que traýan?

Los jaezes y cavallos

de su gente y atavíos

tan sobrados

¿dónde iremos a buscallos...? ${ }^{57}$

¿Qué se puede deducir de este contraste? Pues que pese a su innegable parecido formulístico, es mucho más improbable el vínculo genético efectivo entre el planto sefardí y el castellano que la posibilidad de que sus coincidencias sean casuales y obedezcan a que ambos beben de manera autónoma del casi universal recurso poético del ubi sunt. Aunque las Coplas - remarco el título de Coplasmanriqueñas conocieron un extraordinario éxito editorial y se difundieron en innumerables pliegos de cordel por gran parte del mundo hispánico hasta el siglo XVIII, lo que mejor cuadra con la cultura judeoespañola de aquella época es pensar que los copleros sefardíes heredaron el recurso poético del ubi sunt de los dos mundos literarios e ideológicos con los que más cercanía y familiaridad tenían: las fuentes bíblicas y la patrimonial poesía en hebreo, que cultivaron - como tantas otras escuelas - tal recurso formulístico ${ }^{58}$. Hace años Francisco Caravaca, al analizar "La qasida de Abul Baqa el rondeño y algunas Coplas de Jorge Manrique» "s9, llegaba a la conclusión de que el poema árabe y el castellano habían bebido y utilizado el recurso del ubi sunt de manera independiente el uno del otro. Lo más probable es que algo así haya sucedido en el caso de La destrucción del Templo sefardí, que se enmarca en todo caso en un tipo de composición y en una tradición de plantos por la pérdida del Templo tan acendradamente judía y sefardí que no le añade ni le resta un ápice de originalidad ni de belleza el que estén o no

57 V. Beltrán (ed.), Jorge Manrique: Poesía, vs. 181-186, 193-204 y 223-226.

${ }^{58}$ Sobre su antigua y multicultural difusión, cfr. principalmente M. MORREAle, "Apuntes para el estudio de la trayectoria que desde el "iubi sunt?" lleva hasta el "¿qué fueron?" de Jorge Manrique", Thesaurus XXX (1975) 471-519; y véase el resto de la bibliografia que cita Vicente Beltrán en su edición de la Poesía de Manrique, pág. 214.

${ }^{59}$ Su estudio se publicó en el Boletín de la Biblioteca Menéndez Pelayo XLVI (1970) 171-259. 
estén -y probablemente no están- entre sus influencias lejanas las Coplas de Manrique.

La COPLA de La VOCACIÓN dE ABRAHAM Y EL MOtivo DE EL NIÑO EN EL HORNO

Si en el ejemplo anterior se planteaba un problema de indefinición de fuentes que, a pesar de ello, apuntaba en la dirección de la tradición judía como modelo formulístico de una copla sefardí, en el siguiente ejemplo tal posibilidad se convierte de probable en indudable. La copla $\mathrm{n}^{\mathrm{Q}} 3$ de la Selección de Elena Romero, La vocación de Abraham, constituye en cierta medida el negativo, la otra cara de la moneda, de la mayoría de las coplas que hemos analizado; porque, aunque tiene paralelos en los dos polos fundamentales entre los que fluctúa el mundo sefardí, evidencias innegables señalan a lo judío bíblico-midrásico, y no a lo hispánico peninsular, como modelo último. La vocación de Abraham se basa en la leyenda del tormento, ordenado por el rey Nimrod, del niño Abraham en un horno del que sale milagrosamente vivo. La anécdota no se personifica en Abraham en el relato bíblico, aunque en Daniel 3 aparece una fábula muy similar, la de los tres jóvenes judíos que se niegan a adorar un ídolo de oro construido por el rey Nabucodonosor y salen indemnes del suplicio del horno. En las leyendas midrásicas, sí es Abraham el protagonista del milagro, lo que revela un vínculo indudable con la copla sefardí ${ }^{60}$. La relación directa con el episodio bíblico de Daniel 3 también parece hallarse superpuesta, ya que en la estrofa 15 de la copla sefardí hay un episodio en que Abraham

entrando en el horno iba caminando, con sus malajim iba paseando.

Detalle coincidente con el libro de Daniel, en que los jóvenes caminan por medio del fuego acompañados por un ángel que les protege. En cualquier caso, el entronque de ambas fábulas - la de Daniel y la de Abraham- con la tradición bíblica y midrásica, y el

${ }^{60}$ Véase L. GinzBerg, The Legends of the Jews, Filadelfia 1946, I, págs. 198-203; y E. ROMERo, La ley en la leyenda: relatos de tema biblico en las fuentes hebreas, Madrid 1989, págs. 162-167. 
hecho de que tanto los tres jóvenes judíos del relato de Daniel como el Abraham sefardí caminen por el horno acompañados de sus ángeles me parecen coincidencias que refuerzan la obviedad de la conexión entre todas estas ramas judías y sefardíes. Los elementos comunes son, en cualquier caso, mucho más significativos que los que podrían apreciarse en relación con fábulas del mismo tipo difundidas en toda la Edad Media europea y española, como ejemplifican, entre otras composiciones, un Milagro de Berceo y una Cantiga de Alfonso $\mathrm{x}$ que presentan un niño judío converso al cristianismo que sale indemne del horno al que le arroja su intolerante padre, pero sin caminar por él ni ser acompañado por ningún ángel, lo que -entre otras cosas - le diferencia netamente de la rama de versiones judías y sefardíes ${ }^{61}$.

\section{CONCLUSIONES}

La coincidencia en la denominación de coplas, en el formato editorial típico del pliego o pequeño folleto, en la naturaleza fundamentalmente narrativa, en los recursos propios de la escritura, en el estilo artificioso, en la función cantable, en recursos formales tan característicos como la estrofa, la rima o el uso del acróstico, en determinados contenidos ideológicos y morales, en funciones y temas comunes como el noticierismo o las catástrofes naturales, nos permiten concluir que existe una relación de influencia formal y funcional efectiva entre la poesía de cordel hispana y las coplas sefardíes.

Tal influencia es, sin embargo, mucho más abstracta y general

${ }^{61}$ El Milagro de Berceo es el decimosexto de la serie de los Milagros de Nuestra Señora, convencionalmente titulado "El judezno", mientras que la cuarta Cantiga de Santa María de Alfonso X el Sabio lleva el encabezamiento: “Esta é como Santa María guardou ao fillo do judeu que non ardesse, que seu padre deitara no forno". Sobre ambos episodios, sus fuentes latinas medievales y correspondencias europeas, véanse principalmente los estudios de J. SAUGNIEUX, Berceo y las culturas del siglo XIII, Logroño 1982, págs. 73-102; H. BoRELAND, “Typology in Berceo's Milagros: the Judiezno and the Abadesa presaña", Bulletin of Hispanic Studies LX (1983) 15-29; V. Hatton - A. Mackay, "Anti-Semistism in the Cantigas de Santa María", BHS LX (1983) 189-199; J. E. KELLER, Las narraciones breves piadosas versificadas en el castellano y gallego del Medievo, (trad. A. A. Fernández-VázQuez, Madrid 1987, págs. 84-88); E. FRANCHINI, "Abracalabra (los exorcismos hispanolatinos en el códice de la Razón de amor)", Revista de Literatura Medieval III (1991) 77-94, 84-85; y F. Carrasco, "Un modelo generativo para los Milagros de Nuestra Señora", Revista Canadiense de Estudios Hispánicos XVII (1992) 1-18. 
que la que ha operado desde el romance y la canción hispánica hacia los géneros homólogos sefardíes; y no cuenta con títulos documentados en ambas tradiciones que permitan situar las coincidencias en el dominio de la relación genética directa y estrecha, como sucede con los otros dos géneros. De lo que no hay duda es de que las coplas españolas han proporcionado a las sefardíes el nombre y algunos elementos genéricos básicos; que la tradición judía le ha dado también motivos y elementos ideológicos fundamentales - son muchos los ejemplos que se podrían añadir a $L a$ destrucción del Templo y La vocación de Abraham-; y que con esos entramados, la musa creativa judeoespañola ha construido un género de acusada y castiza personalidad propia, que refleja extraordinariamente las creencias, cultura y modo de vida sefardíes, y que atesora títulos, temas y registros de gran originalidad, interés, y belleza poética.

\section{RESUMEN}

Las coplas sefardíes son, en comparación con el cancionero y el romancero, el género más judío y sefardí del repertorio poético judeoespañol, desde el punto de vista del contenido y la ideología. Sin embargo, su relación con el género de la poesía de cordel panhispánica es también evidente, y se manifiesta en sus coincidencias de denominación, formato, transmisión, estilo, carácter narrativo, metro, rima, recursos formales y temas.

\section{SUMMARY}

Sephardic coplas are, in comparison with songs and romances, the most Jewish and Sephardic genre of Judeo-Spanish poetic repertoire - under the point of view of contents and ideology. Nevertheless, their relationship with Panhispanic chapbook poetry is also evident, and becomes manifest in their coincidences of denomination, format, transmission, style, narrative character, metre, rhyme, formal ressorts and subjects. 